news feature

David

versus

Goliath

Resources are shifting from small labs led by one researcher to large teams with expensive equipment. But has the rise of big biology gone too far? Erika Check investigates.

$J$ ames Watson and Francis Crick are often cited as the ideal role models for modern team science. Watson was a physicist who crossed over into biology, Crick a zoologist who soon turned to genetics. In the early 1950s, the pair shut themselves in a laboratory in Cambridge, UK, to solve the structure of the basic molecule of life - DNA. When they emerged, they reported a discovery that transformed biology into an information-based science the precursor of systems-focused biology.

Today, funding agencies around the world are trying to replicate the conditions that allowed Watson and Crick to succeed. They are spending vast resources on multidisciplinary centres aimed at bringing biologists together with chemists, physicists, mathematicians and others, in the hope that new interactions will bring fresh insights to biological problems. Funding agencies are also investing more in technologies and tools, instead of research projects, in a bid to build huge treasure troves of information.

Scientific leaders agree that collaborative projects can produce results that would be impossible for specialized individuals working alone to achieve. But some are worried that the systems-biology revolution, which focuses on the interaction between cogs in the machine, instead of on the cogs themselves, has undermined the foundations of discovery-based science. They wonder if money spent on technology would be better spent on training scientists to think through complex problems. And they are asking whether large projects waste money in bureaucracy, and dilute creativity by forcing a focus on specific diseases. Is there any basis for these anxieties? Or are today's reforms

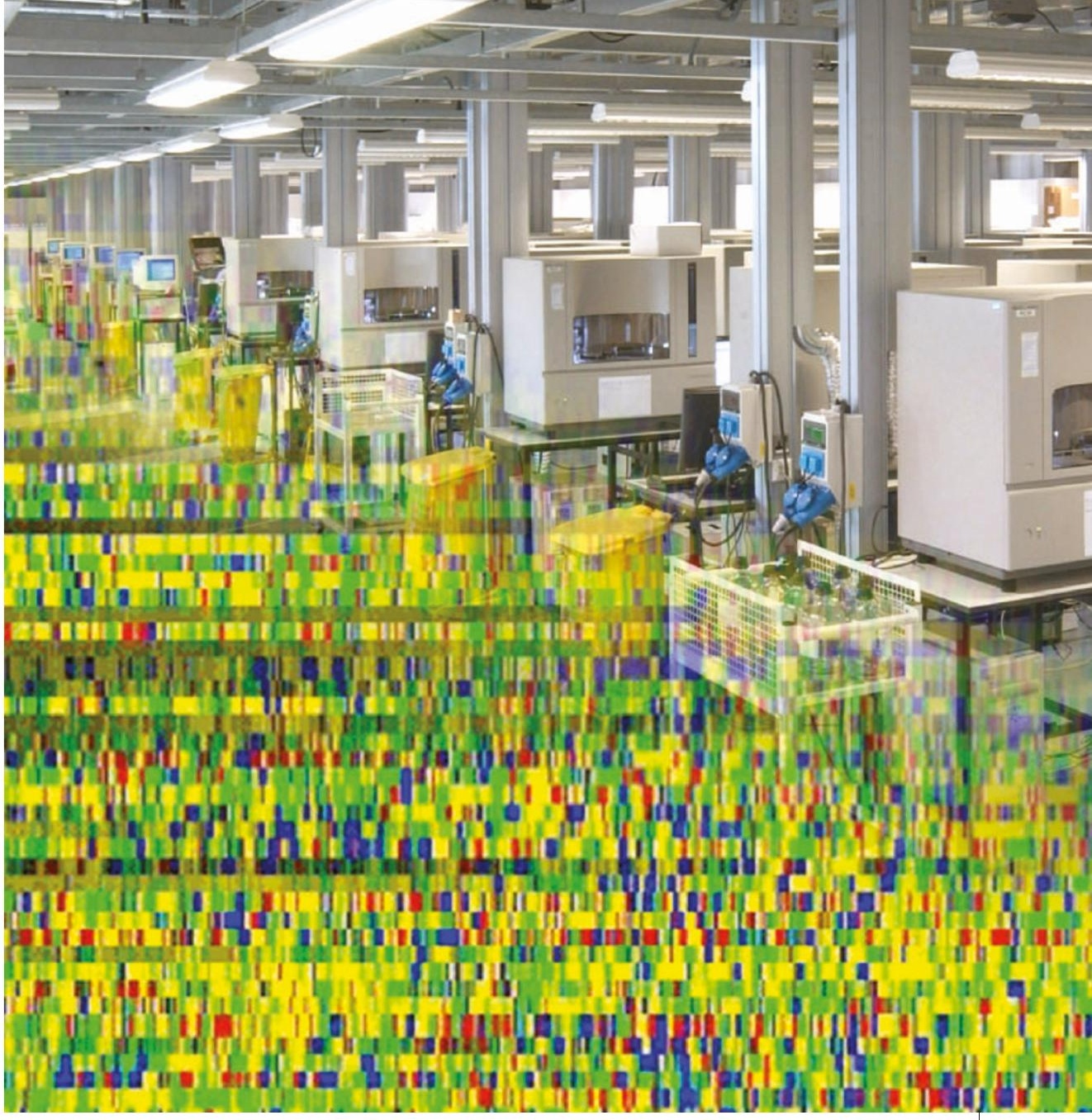

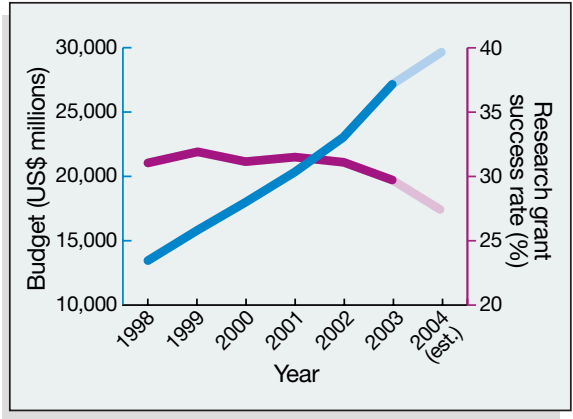

simply taking biology out of the Stone Age?

The debate is particularly heated in the United States, where a recent doubling of federal funds for biological research was accompanied by a decline in successful grant applications, suggesting that there is a shift towards larger projects (see chart). Concerns about such moves can be heard in Europe as well, but the more fragmented nature of funding sources there means that the trend is less dramatic and may even be reversing. China on the other hand is weathering harsh criticism from some of its leading scientists over its tendency to tackle research in the same way it approaches dam building: on a massive scale.

In the United States, the National Institutes of Health (NIH), the world's largest biomedical-funding agency, is going through a revolution under director Elias Zerhouni. He took the helm in 2002, just as the agency's budget was completing a five-
The multidisciplinary approach of Francis Crick and James Watson (right) helped inspire 'big biology' centres such as the Wellcome Trust Sanger Institute (above). The falling success rate for funding of individual projects at the NIH despite a rising budget (left) emphasizes the trend.

year doubling. Zerhouni declared that the NIH needed to do a better job of translating its research into cures. "Biomedical research is at an important turning point that may require new strategies," he said at his confirmation hearing in April 2002.

\section{Thinking big}

Now that the doubling of the NIH's budget is complete, there are some indications that large-scale science has benefited more than traditional, investigator-initiated research. One closely watched barometer is the 'success rate' - the percentage of grant applications that receive funding. In lean times, success rates drop, and individual investigators feel the pinch as they have a harder time getting funding. But success rates for research project grants have dropped overall since the beginning of the budget doubling, from $31 \%$ in 1998 to a projected $27 \%$ next year, according to NIH data. And success rates for new investigators starting research labs have also dropped slightly, from $24.9 \%$ in 1998 to $24.1 \%$ in 2003 , down from a peak of $25.9 \%$ in 2000 .

So why are success rates dropping despite 

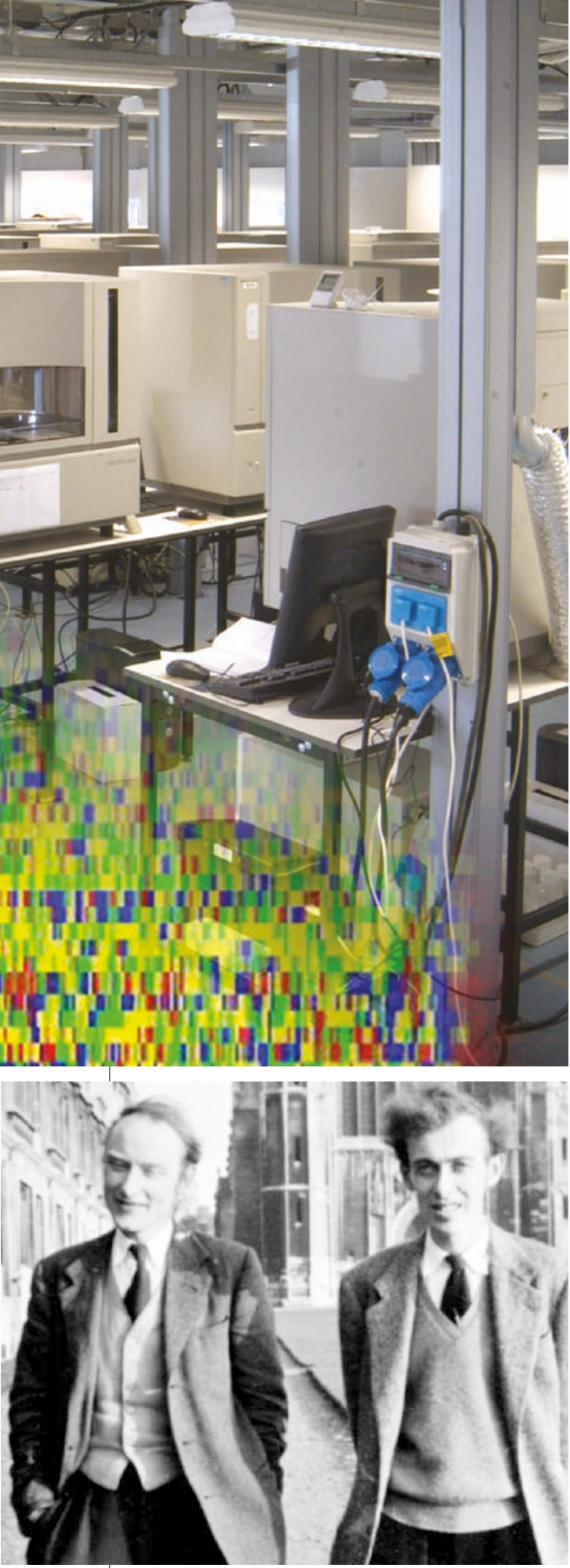

the rise in funds? Part of the reason is that more of the cash is going to research centres, which support groups of investigators who agree to work on a designated problem. By the end of 2005, the NIH's spending on research centres will have grown by $131 \%$ since 1998 compared with only 97\% for research project grants.

These indicators are concerning some scientists, especially those just starting out, who rely on individual project grants to set up new labs. "It is definitely worrisome," says Arash Grakoui, a virologist and immunologist who in July began building his first lab at Emory University in Atlanta, Georgia. "As a new investigator, it is even a little discouraging." Grakoui says that he is increasingly realizing that no single investigator can do everything alone, and that large, team-focused grants are essential tools to solve some problems. But, he adds, new investigator grants, known as $\mathrm{R} 01 \mathrm{~s}$, are essential because they allow young scientists to stake a claim for themselves. "R01s enable energetic, young principal investigators to look at things from a fresh perspective," Grakoui says.

Zerhouni insists that the NIH is not abandoning the individual investigator. The important trend to note, he says, is that success rates per investigator have risen from $30.5 \%$ in 1996 to $34 \%$ in 2003 , even as overall annual rates have fallen. This means that more individuals who apply for funding eventually receive it. "Our intent is to keep the portfolio balanced and I don't see a significant shift towards agency-initiated or large-scale science," Zerhouni says.

\section{All mapped out}

But some biologists are also worried about a more fundamental shift. As part of his vision to move more basic science into the clinic, Zerhouni implemented a plan a year ago called the 'Roadmap' to fund more projects that focus on technologies, team science and clinical research. Although it will eventually account for only $1 \%$ of the $\mathrm{NIH}$ budget, it seems to have propelled other changes in funding priorities.

For instance, in August the agency updated its peer-review criteria to accommodate interdisciplinary, translational and clinical projects better. The 'significance' category used to omit any mention of clinical research, but it now asks reviewers to consider whether "scientific knowledge or clinical practice" will be advanced by the funding application. And in October, the National Institute of Mental Health completed a plan to shift its focus from basic research to projects that target specific diseases.

Zerhouni agrees that the Roadmap is causing fundamental changes at the $\mathrm{NIH}-$ but he argues that such changes are long overdue."We need to tackle complex biology in ways that favour our ability to solve these problems, and we need to tackle the issue of bench to bedside," he says.

Zerhouni is not alone. In Europe, research leaders such as geneticist Rudi Balling, scientific director of the German Research Centre for Biotechnology in Braunschweig, are lobbying for more 'big science' projects. "There is no way around interdisciplinary work," Balling says. "We need to build networks so that large investments can be shared."

But this is more difficult to do in Europe than in the United States, where one agency controls the whole research budget. Jacques Remacle, a scientific officer in the European Commission's research directorate, says that, in Europe, research funding for biology comes from many different sources, requiring agencies to team up to compete with the United States on large projects. "Only a few countries, such as Britain and Germany, can afford large initiatives," he says.

Some even sense a retreat from big biology in Europe. For instance, German federal funding for the National Genome Research Network, set up in 2001, will decrease from the $€ 180$ million (US\$237 million) that covered its first three years to a projected $€ 135$ million for the next three. Hans Lehrach of the Max Plank Institute for Molecular Genetics in Berlin laments the decline. "Investments for large-scale projects are moving backwards and now most of the funding is going back to classical research," he says.

China, on the other hand, has the opposite problem. Last year, Premier Wen Jiabao initiated a strategy for the next 15-20 years called the National Mid-to-Long Term Plan for Science and Technology. This advocates funding for large 'megaprojects' costing anywhere from hundreds of millions to billions of dollars.

But Chinese scientists around the world are warning that this may not be the best way to spend research money. They allege that science is still too intermingled with politics in China, and that money may be wasted on bad projects. They want the government to build up the country's scientific talent and resources by investing in more small-scale research first, before committing to huge, top-down projects.

"Organizing big projects without a sufficient number of high-quality researchers ... will undoubtedly lead to the waste of resources," writes $\mathrm{Mu}$-ming Poo, director of the Institute of Neuroscience at the Shanghai Institutes of Biological Sciences, in a recent supplement to Nature in Asia (see Nature 432 (Suppl.),A18-A23;2004).

\section{Central perks}

The worldwide commitment to big biology stems partly from the success of the Human Genome Project, which spurred the growth of large sequencing centres everywhere from the Wellcome Trust Sanger Institute near Cambridge, UK, to the RIKEN Genomics Sciences Center in Yokohama, Japan. At the same time, biology is now asking questions about complex networks of cellular signals that require groups of specialists taking a team approach. A number of large research centres have been built for this purpose, such as the US\$150-million James H. Clark Center at Stanford University in California, which was funded by a private donation.

But in the United States at least, the shift has had as much to do with politics as the needs of research. The idea of doubling the 


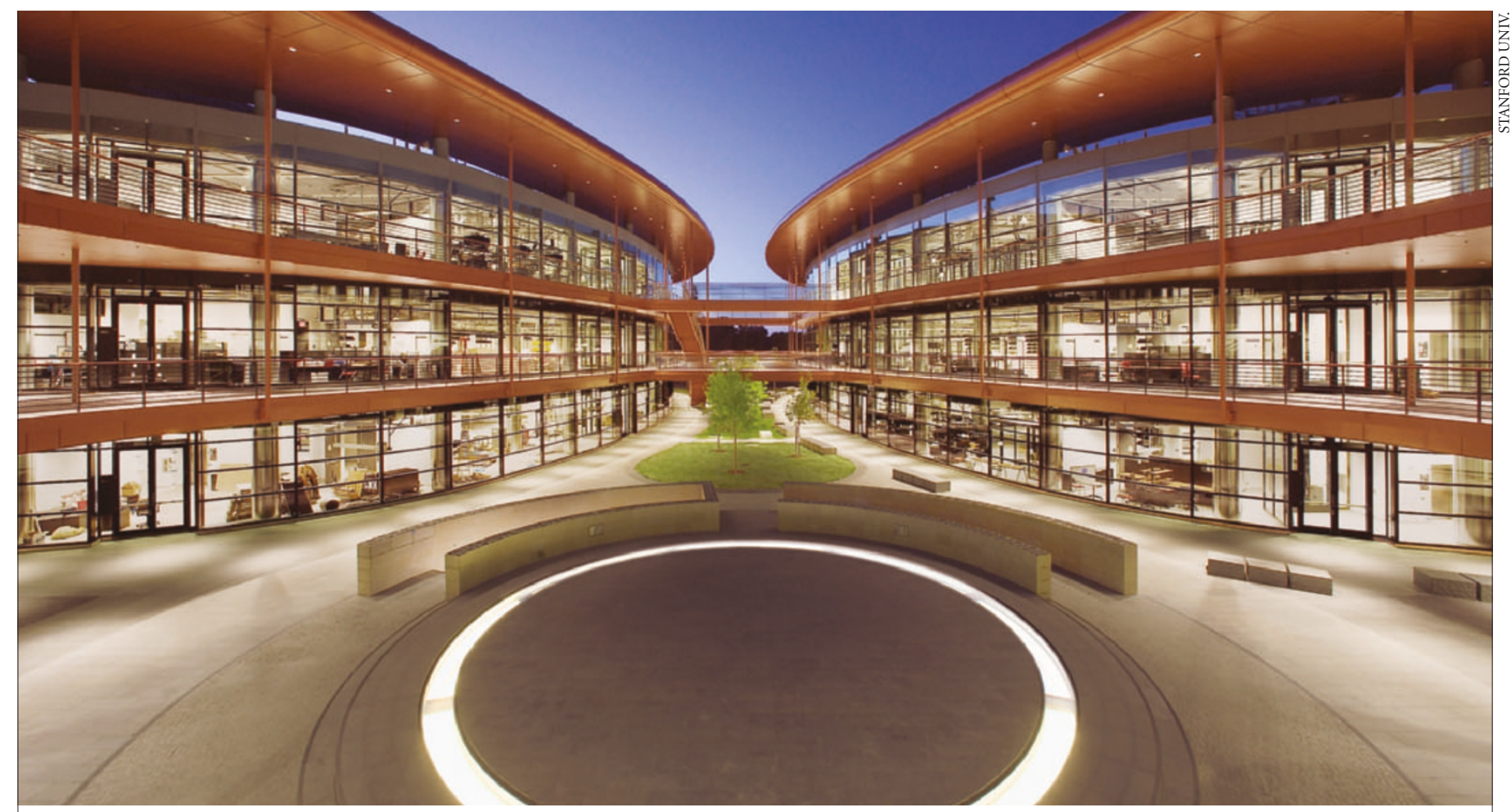

Group therapy: the James H. Clark Center at Stanford is a new multidisciplinary institute that was built to tackle some of biology's toughest problems.

NIH's budget was supported by a broad coalition of universities, scientists, research institutes and patient advocates. These groups lobbied tirelessly during the early and mid 1990s for the rise. The genome project helped them to convince lawmakers that science was proceeding in new ways, and that the NIH needed to grow so that US science could keep pace.

"If we had wanted to stay with R01 science, we probably wouldn't have gotten past a \$13-billion or \$14-billion agency," says April Burke, a lobbyist for biomedical research in Washington DC, who was heavily involved in the doubling. "It was the fact that we were changing that allowed policy-makers to say, 'Yes, I will invest in what you're doing.."

\section{Team spirit}

Many basic biologists are supportive of the shift towards team science, and agree that researchers should think more about medicine. Nobel laureate Paul Berg, a biochemist at Stanford University, is among them. He says that 20 years ago, graduate students weren't interested in medicine. "But today," Berg says, "you see graduate students in basic science coming to clinical seminars. The expectation is that somewhere, somebody's brain is going to recognize that what they're doing applies to some disease." $\mathrm{He}$ agrees that a shift too far towards clinical research would be bad for the NIH, but he doesn't think that this has happened yet.

Signs abound that the team mentality is taking hold. While young scientists all hope to earn individual support to start their careers, they are acutely aware of the need to

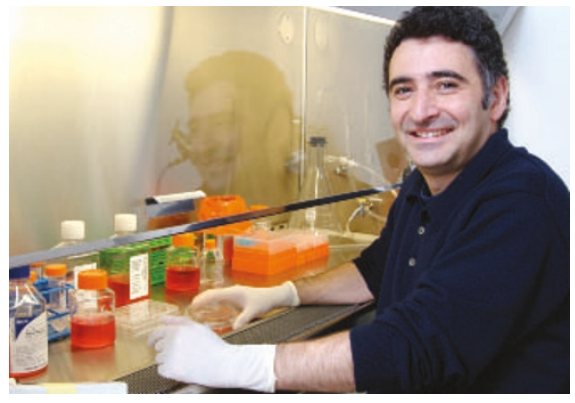

Left out: Arash Grakoui worries projects centred on individuals are being sidelined by big biology.

form teams, to gain access to expensive equipment, and to take advantage of where the funds are flowing.

"You have to think in terms of the best investment strategy, where you try to diversify a little and apply not only for R01s, but also for other opportunities," says John Wherry, an immunologist who in January will start his first lab at the Wistar Institute in Philadelphia, Pennsylvania. Wherry has watched as higher and higher merit scores - the numbers assigned by review boards to grant applications - have become necessary to win an R01 grant, while the requirement for centre grants has remained stable. "If it's possible to get involved with some larger submissions that's going to provide a better opportunity for junior people right now," he says.

Although many see the shift as a positive thing, the real problems may still lie ahead. At the end of its budget doubling, the NIH has enough money to spread around many different kinds of projects. And a \$1.7-billion cash infusion for biodefence research has also boosted the agency's bottom line. But the years ahead don't look so flush. The biodefence bonanza is over, and after years of double-digit percentage increases in its budgets, the NIH received just a $2.8 \%$ increase for this year, and will get a $2 \%$ increase for 2005 .

A massive budget deficit and a clampdown on all spending outside of homeland security and defence mean this situation will persist for the foreseeable future. This is what keeps some science advocates up at night - they realize that it is easier to trim new investigator grants than to cancel funding already promised to large research centres. "We certainly are concerned," says Paul Kincade, an immunologist at the Oklahoma Medical Research Foundation and current president of FASEB, a coalition of American biomedical research societies based in Bethesda, Maryland.

It's difficult to know what all these changes mean for scientists who want to follow in Watson and Crick's footsteps. The team approach promises to advance the work of basic scientists, but researchers need the freedom to pursue new ideas about biology - even if it's not clear how they will have an immediate impact on patients' lives. With its coffers relatively full, the NIH is in a position envied around the world: it can fund both large-scale and small biology. But if US funding for science drops, the agency may be forced to make some tough choices. "As things tighten up, as they seem to be doing, we need to protect individual investigatorinitiated science," Kincade says. 
families access to top labs across Hungary. And Ignaas Verpoest, a Belgian materials scientist, won a share of the prize for a travelling roadshow on composites.

The $€ 1$-million Descartes Prize for Research was awarded to collaborations working on quantum cryptography and mitochondrial diseases.

\section{Female 'passion patch' turns off FDA safety panel} Washington A testosterone patch for women was unanimously rejected last week by an advisory panel of the US Food and Drug Administration (FDA). The Proctor \& Gamble product, Intrinsa, was expected to be approved for use by women who have lost their libido after the removal of their ovaries.

Panel members said they were concerned that the hormone might increase the risks of cancer and heart attacks, and called for larger and longer clinical trials to verify the patch's safety. Industry watchers speculated that the caution stemmed less from the safety and efficacy of the data in hand than from nervousness at the FDA following recent safety controversies, even though the advisory panel is independent of the agency (see Nature 432, 537; 2004). The FDA is not obliged to take recommendations from its advisory panel, but usually does.

\section{Angola trumpets mine-clearing mission}

Paris A project was launched last week to clear mines sown during three decades of Angolan civil war and open an old elephant migration route linking Botswana with Zambia and Angola.

Botswana's growing elephant population is threatening agriculture and vegetation, and reopening the route is the only way to avoid massive culling. The US\$1-million project is funded by Roots of Peace, a California-based group that works to turn minefields into farmland. The plan was announced last week at the Nairobi Summit on a Mine-Free World.

"The threat to people from these seeds of misery must be our first concern but it is clear

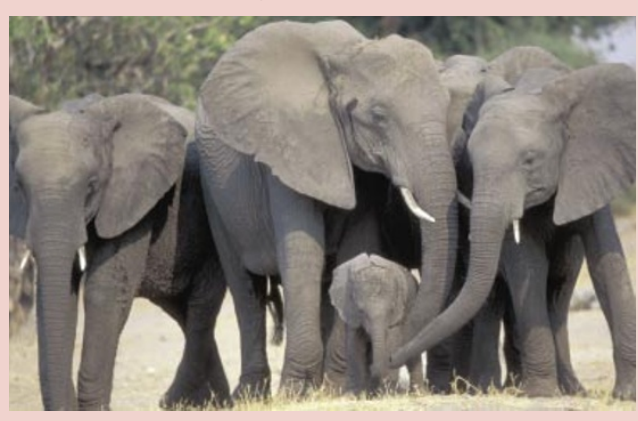

that the environment, upon which local people depend for food, shelter and natural medicines, suffers too," says Klaus Toepfer, executive director of the UN Environment Programme.

\section{Row over axed courses hits UK government}

London The sound of axes falling on British science departments has finally reached the government's ears. Charles Clarke, the education secretary, wrote to the Higher Education Funding Council for England last week, asking what "encouragement and incentives" could be made to protect subjects of "national strategic importance" that are at risk, including chemistry, physics and maths.

David Giachardi, chief executive of the
Royal Society of Chemistry, called the statement "a bit thin and a bit late". For example, the University of Exeter recently decided to close its chemistry department (see Nature 432, 543; 2004) and the University of Newcastle upon Tyne is to abolish its pure physics degrees.

\section{Correction}

In our News Feature "David versus Goliath" (Nature 432, 546-548; 2004), we mistakenly switched Watson and Crick's training: Watson was the zoologist, and Crick started as a physicist. 